\title{
A new endeavour
}

\author{
The Editors
}

$\mathrm{O}$ ver the past 13 years, we have published more than a thousand scientific research articles. Many thousands of scientists have trusted us to manage the assessment of their work and, all being well, disseminate it to the scientific community. We have been supported in this endeavor by Nature Publishing Group, who have been our publishing partners for most of the journal's history. It has been a long and fruitful partnership, but the time for change has come.

The scientific publishing landscape is shifting in many directions. New vistas are opening up and finding our way across them-as scientists and editors-requires a change in perspective and the independence to do new things. EMBO is therefore launching its own scientific publishing identity, EMBO Press, in partnership with Wiley and HighWire Press, who will help us to realize our vision of fair, transparent and data-enriched scientific publishing. EMBO Reports will be an integral part of this endeavor: we will continue to apply and improve the EMBO Press editorial policies, including transparent peer-review, scooping protection, referee cross-commenting and the source data initiative, and we will continue to provide a forum for discussing the wider impact of and issues surrounding the scientific endeavour.

EMBO Press will be a shared identity for the four EMBO journals: EMBO Reports, The EMBO Journal, Molecular Systems Biology and EMBO Molecular Medicine. As such, it will serve as a platform for our policies and initiatives, guided by the scientific community at large and by our international advisory boards of leading scientific researchers. We hope that a single, strong voice that pushes for greater fairness and transparency in the interest of the scientific community will improve the way that science is communicated and used, and that scientists are assessed. We understand that the true driving force of science is not money, fame or fashion; it is curiosity. Scientists ask questions about the world and work carefully to discover answers. We would like to publish those answers in a way that is fair to authors and useful to our readers and those who will revisit these questions in the future.

What does this mean for EMBO Reports? For more than a decade now, in addition to high-quality, short-format scientific reports and accessible reviews, EMBO Reports has published Science \& Society articles on the broader impact and implications of scientific research. We hope that EMBO Press will become home to an active community of engaged scientists for discussing such issues, including science research, practice, policy and, of course, publishing. Ideas and conversations might evolve into 'formally' published content in the EMBO Press journals, whilst EMBO Reports' thought-provoking articles and editorials will gain a new platform for dissemination and debate.
The most obvious and immediate change, then, is the launch of the $E M B O$ Reports website, alongside the new EMBO Press platform. This will not just be a cosmetic makeover: in the months to come, we will make significant enhancements to the way that we help scientists present their data, making it more accessible and reusable, improving the experience for both authors and readers. We will also continue to refine our editorial policies, based on community feedback, to ensure that the assessment and publishing experience at the EMBO Press family of journals is among the fairest and most transparent. Together, these improvements will allow EMBO Reports to continue its mission of publishing groundbreaking, relevant observations that are both exciting and reliable.

EMBO Press stands for a better way of tackling the publication of science, backed up by some thoughtful editorial policies and innovative ideas for technologies. As such, EMBO Press is a compass pointing in the direction we think we should take across the changing publishing landscape. We hope that our authors and readers will agree with us on the direction and lead us onward. It is an ambitious goal, but EMBO has always been about setting high standards and good examples. EMBO Press is the next step on the journey, and the editors of EMBO Reports are excited to be along for the ride.

DOI 10.1002/embr.201338177 